Dr. C. R. Woovson, St. Joseph, Mo.: The teacher, perhaps, should be instructed along these lines, and the parents should be instructed along the lines of trying to lead the ehild to bear disappointment well. The environment cannot be too good. The habits should be exceedingly regular. As their earrying capacity is not great, they should never be overloaded. The object or idea of rote learning should be condemned in unmeasured terms. The prodigy or the ehild disposed along those lines should be held back. The child who is defective should never be encouraged in the lines in which it shows great proficiency; in other words, the centers that are disposed to develop quickly should be held back, and an effort made to bring up the centers which develop slowly. The labit of parents and teachers of being abrupt with patients like these is very injurious. At the same time too much stress cannot be placed on the necessity of tenching the individual to bear disappointment well. I think that much more good is to come from the schools along these lines than from the medical profession. However, the profession and the school, as has been said, should be closely associated.

DR. William J. G. Dawson, Ildridge, Cal.: At the Glen Dllen Home in Sonoma County we have now 944 inmates of all grades. We have five school departments, but I believe in educating these people through their hands and their feet. It is the only way they can be developed to any extent. The parents do not think so. They want their children to learn to read and write, but there is very little progress made in reading and writing, comparatively speaking,. We ought to start in early with the children in the public schools and find out the "defects" and the backward children. We have both in the Home. There should be a separnte and distinct treatment for these backward children. They should not be mingled with the feeble-minded to the same degree that we have them up there; and it is a very important matter that the sehool teacher should early detect the trouble in the child.

$\mathrm{D}_{R}$. I A nier Crosny, Fruitvale, Cal.: Dr. Orbison is fortunate in the cooperation which he obtained in his cases. But the average parent will be found to be a stone wall, when you seek cooperation about a defective child. Unless the child is almost a fit subject for an institution for the care of defec. tives, the average parent will not acknowledge the necessity. for special care and observation and teaching. In the schooling of the child, it is the tencher who has priority with the pupil, and it is in the psychologic and pedagogic departments of our normal schools and universities that the greatest eflort must be made, looking to the training of teachers to recognize the exceptional child, and to the enlightening of the boards of education in the matter of the care and mental development of the mental irregular. It is a modification of the present plan, classification and training which must be accomplished by you neurologists through the boards of eduention and the teaching force of the state.

DR. DAvid S. Boorh, St. Louis: There was one expression used by the author of the paper which I think is very mis. leading, although it is a common onc, viz., "mental and physical fatigue," thus disassociating mind from matter. It is an exprossion generally used by the profession, and though well understood by the neurologist, it is misleading to the laity (if not to the average practitioner), who do not recognize the fuct that general physical fatigue lends to "mental" fatigue; and that "mental" fatigue is an evidence of physical fatigue. In the treatment of these diseases, the error is of ten made of adding physical fatiguc to the already present "menonly fatigue, which, instead of aiding the reparative process, y aggravates the original trouble.

Dle. Louise PATrerson, Vineland, N. J.: What we need is An enlightenment of the tercher along these lincs. The teacher needs to have an opportunity to observe the grades of chil then, so that she may weed out those who are suffering from be; if conditions, and that they may be put where they should min if they are feeble-minded, in an institution for the feebleanded; if they are backward, in classes for the backward; and if they are neurotic, they may be sent to the physician. We also need physicians and medical inspectors who know than hast finding out if the child has measles, or looking at its throat, or looking into its eye, or seeing if it has a discharging otitis media. We need physicians who will go deeply into this subject, and we need men and women who will care for these children and have then trained in the way they should be trained. We have a training school in our institution for both physicians and teachers. This has been going on for a number of years. It is not probable that many of you have ever heard of it.

Dr. Bernard Oetringer, Denver: Tho point that we must reach in investigating these conditions is to feel the necessity of putting these children in a place where they will feel at lome. We are probably learning to recognize earlier than heretofore, nbnormal mentality of childhood, but when done, there are few suitable pluces for these children. We have an occasional home for the feeble-minded, but even in these care is not individualized. Workers who are constrained by their daily labor to do their physical utmost cannot well recog. nize an unusual condition in their children. Amongst another class, the father and mother are so busy looking after bus. iness and home that they do not recognize abnormality, while amongst the very rich, little personal attention is paid to boy and girl. The protection of those mentally inadequate has much to do with economic conditions, and with that comes the need for recognition and care by authority outside the family. They should live in colonies where mental stress can be removed by education suitable to mental development and absence of uneven family discipline and sentimentality. Unless I am mistaken, I did not liear from Dr. Moore whether he had any hopes of recognizing a preneurasthenic or a preinsane condition. I have never felt that I could, and I think after all this is for to-day merely a hope.

Dr. Ross Moone, Los Angeles: We are establishing a school laboratory in Los Angeles along the lines of the Philadelphia laboratory for the study of children from the standpoint of their nerve and mental makeup, particularly the latter. The object of this paper was to make concrete three juvenile types of mentality who may be so brilliant as to seem normal and who in the future may become ill from preventable conditions. I hope to see in the future a series of questions or a mode of examination developed which will lead to an accurate knowledge of these types. There is one thing that goes back of the remarks made with regard to the education of the general public-the education of the general practitioner. These potentially substandard children slip through our examining rooms unrecognized. 'This is because the types of childhood on which mental or nervous disease engrafts itself are not concretely in the minds of the examiners as are the types of pliysical defect. It is my belief that if we neurologists will study to elaborate such types as have been hinted at in this paper we will do a great service to future generntions by making possible the prevention of much mental and nervous discase.

\section{A CASE OF ASCENDING PARALYSIS WITH RECOVERY}

CHARLES W. HITCHCOCK, M.D.

Attending Neurologlst to Harper IIospital DETroIT

Patient.-The subject is a soldier in the infantry service U. S. A., aged 24, with negative family and persomal history, who had had th army sorvice of four years ten months and had served in the Plilippines two years three months. There is no history of venereal disense or of venereal or alco. holic excesses.

Examination.-He was first seen by me in consultation with Mrior F. M. Hartsock, U. S. A., July 30, 1010, and had first reported at sick-call July 27, when he appeared rather dull, sallow in color and with a temperature of $100 \mathrm{~F}$. and pulse 76 . He was constipated, his tongue heavily coated, marked anorexin, and he presented the appearance of the onset of an acute infection. The spleen and liver were not enlarget. July 28, the Widal test was negative as also the urinalysis; on July 29 the patient had to be catheterized.

History.- He told me that July 22 he had noticed the first symptoms, feeling chilly and having some headache and ho 
thought he had some fever. During the last three days (July 27 to 30 ) his temperature had ranged from $99.8 \mathrm{~F}$. to $102 \mathrm{~F}$. and was at this time $100.2 \mathrm{~F}$. with a pulse of 72 , full, soft and regular. He had been vaceinuted against typhoid some nonths previously. 'lwo weeks before the onset of the illness he had been on a "hike" across country but had not been in contact with the siek and had been in no house where either chus or adult was sick or paralyzed. He spoke of much backache. "in the small of the back," ns anong his first symptoms but complained of no other prins. He was examined in bed in the post hospital and seemed mentally clenr. He could nove one foot slightly and could move a little the toes of both feet but otherwise could not move his lower extremities at all. Though he said he had evacuated his bladder the day before, lie was now totally unable to do so. There had been no bowel action on July 30 , though good until then.

Coursc.-The knee-jerks were entirely abolished; the armreflexes were present and a trifle more quick than normal. There were no sensory changes.

August 3: The patient seemed comfortable but motor paral. ysis had distinctly advanced and extended to the traperius muscle. The deltoids were involved but he still used hands and forearms. Electrical response of muscles was reported as very slugrish. The speech was fairly clear yet sounded a bit thick. Re;piration is affected; has been as high as 36 per minute and there lawe been periods of quite typical Cheyne-Stokes respiration and also quite a degree of opisthotonos. The patient is able to raise the right arm somewhat but can use only the left forearm. His temperature came to normal August 2, and is practically normal to-dny. He takes fool pretty well; but some saliva escapes from the moutl.

August 5: The pupils are somewhat contracted. The bladder is still paralyzed and the patient has passed urine involumtarily. There has been a mild delirium and the infectious process seems to have involved the knee-joints which are slightly enlarged and quite tender.

August 7: The patient assures me that his knees are not the same as those I tackled before and that he has three now. When asked to show me the third, he recognizes that he has wantered mentally and corrects his error. lemperature is normal, pulse (is and of good quality. There is some difficulty in swallowing.

August 10: For ten days a bedsore has been imminent but has been averted by care. To-day there are points of threatenel trophic disturbance over heels and malleoli and these are carcfully protected. He says he feels "as if all in" in his upper extremities and there is some retraction of the upper lip.

August 14: Patient can hardly use his hands at all or lift his wrists from the bel; there is twitching of the muscles of the face.

August 18: Patient is seen with Dr. Flintermann to-day; he has greatly improved in twenty-four hours; he raises his right arm very well, the left not so well and he also moves toes and feet letter. The triceps reflex is absent, those of forearm and fingers present. There is still entire absence of the rellexes of the lower extremity. From this time on, there was gradual improvement, this being more marked in the upper extremities, thongh that in the right arm and left leg was especially noticenble.

September 11: There was a slightly spastic condition of the left arm and extension beyond an angle of $00^{\circ}$ was painful, the bladder had resumed its functions and the bowels moved without aid.

October 7: A distinct thrill of the left quadriceps extensor is felt on tapping the left patellar tendon, though this is not discernible on the right side. The patient now uses the right hand and arm quite freely and normally, the left with more diffeulty. The ubdominal reflex is still absent. He moves the feet a little better but cannot draw up either leg or flex the knee.

November 17: The patient has improved much more in the upper than in the lower extremitics. His hand-grasps are (relutively) right 40 , left 30 . Cremasteric response is prompt on both sides.
Tan, 3, 1911: There is still some rigidity of left arm. The netivities of the lower extremities are still but slight, though improvement has been murked.

January 25: The left knee-jerk showed a positive, thougl faint return. The patient now flexes the left knee to about (i) ${ }^{\circ}$, the right less.

He passed from direct observation and was discharged from the service February 22 , but on March 17 he wrote that he had improved wonderfully, having about half the use of left leg. June 20: He wrote that the left leg would support about two-thirds of his weight and that he had. been out for a ride.

In other words, this man's problem is the same as that of the patient slowly recovering from acute poliomyelitis, the restoration of the power of individual muscles ${ }^{\circ}$ how best to make other muscles assume the burden of deficient muscles or muscle-groups, and this raises naturally the query as to diagnosis.

Obviously, here is a case of acute ascending paralysis, without true atrophy, with slight sensory phenonen and resembling in many respects the fatal case described by Landry in 1859. Is the case here reported a case of Jandry's paralysis or is it merely an acute ascending paralysis, with improvement of muscle-groups involvel taking place in reverse order and its ultimate status presenting the problems commonly seen in recovering cases of poliomyclitis? Is it not probable that many of the cases which have served to confuse the pathology of Landry's paralysis are only cases of acute poliomyeitis, in which the spinal cords, could they be examined, wonld reveal lesions of a distinctly inflammatory character, presenting quite a different pathologic picture from that in which Landry was unable to denonstrate any definite changes?

\section{LARGE MULTIPIE PROSTATIC CALCULI AS A LATE RESULT OF PERINEAL PROSTATECTOMY}

\section{WALTER D. WEBB, M.D. WASHINGTON, D. C.}

History.-The patient, J. N., white, aged 68, with an unim portant family history, states that seventeen years ago (189t) he was operated on by Dr. Samuel Alexander in New Yolk City, a perineal prostatectomy being performed. This was probably one of the first perineal prostatectomies performed this country. For several years lie was relieved of his $\mathbf{s y}^{\mathrm{mp}}$ toms with the exception of some incontinence, but for thirtect or fourteen years he has suffered wtila a return of the incolv. tinence equal in extent to before the operation and frequent desire to urinate. For ten years he has had to wear a rubber urinal during the day and sleep with a giass urinal between his legs at night. He has never resorted to catheter life owilns to the difficulty of its introduction. There is a marked ale holic history. No erection since the operation in 1894 .

Examination.-On admission to hospital, Sept. 20, 191l, examination showed an emaciated old man with large bon't frame; arteries markedly sclerotic, beady, senile type; liear and lungs negative; temperature was elevated and pulse ace erated. His urine was alkaline, full of pus and mous and few red cells were present; therc was a heavy trace of album and a few hyaline and granular casts. He complained of par at the end of his penis, which was swollen and inflamed, frolng a balanitis set up by the irritation attending constant dribbing of alkaline urine. Residual urine 250 c.c., bladder capacilie only 300 c.c. Urethra admitted a filiform sound with were grentest difliculty; attempts to introduce large sounds we resisted by obstruction in the usual site of the prostatie urethrn. Roughness could be felt at this point, by moving ther filiform. A follower was passed (No. 17 French) into blad to and a click could be felt which was interpreted to be due to stone in the bladder. Followers (to include No. 24 French) were introduced; the urethra was found to be very tort 